\title{
The reversal index and ageing
}

M. A. JEEVES

DEPARTMENT OF PSYCHOLOGY, UNIVERSITY OF ADELAIDE

The discrimination and reversal learning performance of rats was studied at four different ages, from 4 months to 18 months. The Reversal Index (RI) was found to reduce steadily as age increased. The age range studied in the rats approximately covers a range equivalent to childhood to maturity in humans. It does not extend into the period where significant effects due to old age are observed in humans.

A survey of the literature had led us to suggest that reversal learning performance was more sensitive to a variety of variables than discrimination learning (Rajalakshmi \& Jeeves, 1965). These variables included phylogenetic comparisons, ontogenetic development, and a wide variety of treatment variables such as early environment, brain dysfunction, and drug treatments. We suggested that the ratio of trials (or errors) to criterion on the first reversal divided by trials (or errors) to criterion on the original discrimination was one way of expressing this discrimination reversal function, which we named the Reversal Index (RI). In a recent paper further support has been lent to the usefulness of this index by demonstrating its relative independence of differences in either motivational or incentive level or both (Gossette \& Hood, 1967).

The purpose of this paper is to report experiments which represent a systematic attempt to study the changes of $\mathrm{RI}$ with age at four different points in the life span of one species. In a series of experiments on discrimination and reversal learning carried out over the past five years with Norwegian hooded rats, we have used rats of ages ranging from 4 months to 18 months at the time of reversal.

Subjects

Thirty-five Norwegian hooded rats served as Ss. The numbers of $\mathrm{Ss}$ at each age varied since they were determined by the primary purpose of the various experiments in which they took part as control groups. There were nine Ss of age 4 months, 12 Ss of age 5-1/2 months, $10 \mathrm{Ss}$ of age 7-1/2 months, and four Ss of age 18 months.

Task

The apparatus was the same as that used and reported in previous studies (Jeeves \& North, 1956). The stimuli to be discriminated were horizontal vs vertical black and white striped doors. Ss were run for 10 trials a day seven days a week, and the criterion for learning and reversal was $18 / 20$ correct responses on two successive days. A correction procedure was used. The Ss were deprived of food for $23 \mathrm{~h}$ before running. Water was available at all times in thetr home cages and they were given $10 \mathrm{sec}$ feeding in the goal box on each trial, followed by $1 \mathrm{~h}$ free feeding each day at the completion of testing. All the Ss were pretrained to run through gray doors according to the procedure described previously (Jeeves \& North, 1956).

Results

RIs were obtained for each group of Ss by dividing the mean trials to criterion on the first reversal by mean trials to criterion on the original discrimination. Both means were based on scores which included trials on the two days that the criterion was reached. The mean RI values for each group are shown in Table 1 and are plotted in Fig. 1.

Since the youngest $\mathrm{Ss}$ were 4 months and the oldest Ss were only 18 months, we should regard these observed changes as equivalent to covering the range in humans from childhood to maturity. The changes with age observed most markedly in humans from 40 years onward (Welford, 1958) had therefore, presumably, not begun to have significant effects. An analysis of variance revealed a linear component which was significant at the $10 \%$ level $(F=2.08$, df $=1 / 31, .1>p>.05$, one talled).

\section{Discussion}

The results lend support to the view that the RI is sensitive to ontogenetic development up to maturity. As suggested in an earlier paper (Rumbaugh \& Jeeves, 1966), to obtain a reasonably reliable index at any age the estimation should ideally be based on more than a few Ss. Possibly, if the number of Ss in the oldest group had been increased to ten, the results would have reached a higher level of significance. It would be interesting to see whether, in the range from maturity to old age, the RI begins to increase again. Unpublished results with human Ss suggest that it does. The results reported above

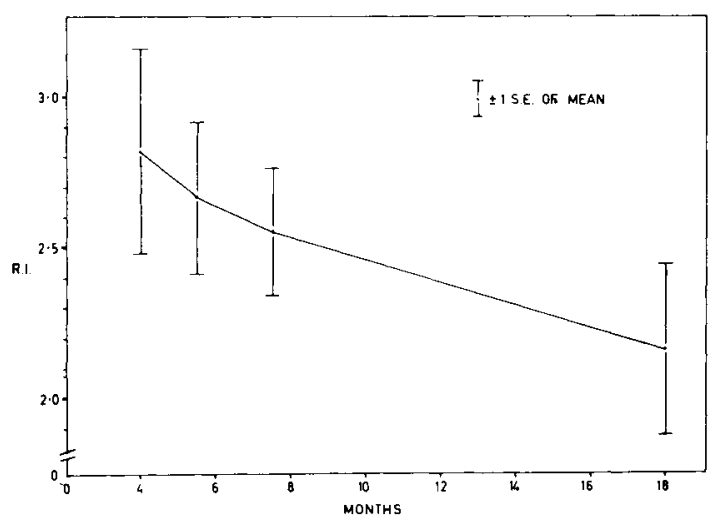

Fig. 1. Plots the relationship of age against RI. 
Table 1.

\begin{tabular}{lcccc}
$\begin{array}{l}\text { Age in } \\
\text { months }\end{array}$ & $\begin{array}{c}\text { Number } \\
\text { of rats }\end{array}$ & $\begin{array}{c}\text { Mean trials to } \\
\text { criterion on } \\
\text { discrimination }\end{array}$ & $\begin{array}{c}\text { Mean trials to } \\
\text { criterion on } \\
\text { reversal }\end{array}$ & Mean R I * \\
\hline 4 & 9 & 5.88 & 17.7 & 2.82 \\
$51 / 2$ & 12 & 8.75 & 23.5 & 2.67 \\
$71 / 2$ & 10 & 9.1 & 22.4 & 2.56 \\
18 & 4 & 5 & 10.5 & 2.16 \\
\hline
\end{tabular}

*The Mean $R I$ is the mean of all the separate $R I$ 's and therefore is not equal to the ratio of the group mean of trials to criterion on reversal divided by the group mean of trials to criterion on the discrimination.

are in agreement with the results we summarized in our earlier review (Rajalakshmi \& Jeeves, 1965). At that time we could find no reports in which discrimination and reversal learning with one species had been studied at more than two different ages.
Now, by taking four ages, instead of only two, we are able to conclude with greater confidence that the RI changes systematically with age, and that this change is in the direction of reduction up to maturity.

References

GOSSETTE, R. L., \& HOOD, PATRICIA. The reversal index (RI) as a joint function of drive and incentive level. Psychon. Sci., 1967, 8, 217.218.

JEEVES, M. A., \& NORTH, A. L. Irrelevant or partially correlated stimuli in discrimination learning. J. exp. Psychol, 1956, 52, 90-94.

RAJALAKSHMI, R., \& JEEVES, M. A. The relative difficulty of reversal learning (reversal index) as a basis of behavioural comparisons. Anim. Behav., 1965, 13, 203-211.

RUMBAUGH, D. M., \& JEEVES, M. A. A comparison of two discrimination-reversal indices intended for use with diverse groups of organisms. Psychon. Sci., 1966, 6, 1-2.

WELFORD, A. T. Ageing and Human Skill. London: O. U. P., 1958. 